\title{
The Historical Context of National Art Exhibition*
}

\author{
Zhaoxia Li \\ School of Fine Arts \\ Zhengzhou University \\ Zhengzhou, China
}

\begin{abstract}
As the most important art exhibition in the New China, the National Art Exhibition has accumulated considerable sedimentary accretion and formed a certain cultural context since the first exhibition in July 1949 till the twelfth exhibition. This paper intends to elaborate on the interrelationship between each exhibition, the interrelationship between the state, the artist and the audience, as well as the problems generated from such interrelationship of the national art exhibition from its function positioning, exhibition mode, evaluation criteria, theme selection, artistic form and other aspects, in order to make a holistic view and sorting of the National Art Exhibition, reveal the positive energy of Chinese art culture as carried forward by the National Art Exhibition, and play a role leading the core values.
\end{abstract}

Keywords—National Art Exhibition; context; fine arts creation

\section{INTRODUCTION}

The term of Context originates from the linguistic category at the beginning, which is the historical category developed in a specific space. From the narrow sense, it is a "cultural context". American anthropologists Ernfen Krober and Clyde Krakowen pointed out: "culture contains a variety of explicit or implicit behavior patterns, and it is learned or taught by virtue of symbols, constituting the outstanding achievements of human; the basic core of culture includes the traditional ideas derived from history and selection, especially the values; the cultural system can be regarded as the product of human activities, but can also be seen as the factor that limits human's further activities." [1] Krakowen defines "context" as "the pattern of survival created in history". The author aims to show the interrelationship between each exhibition, and that between the state, the artist and the audience, as well as the problems generated from such interrelationship, so as to make a holistic view and sorting of the National Art Exhibition.

Since the first National Art Exhibition in July 1949 till the present, from exploration to maturity, it has found and cultivated a large number of outstanding painters for the country, and selected many excellent works of fine arts as the national wealth. As the most important art exhibition in China, the twelve National Art Exhibitions have accumulated considerable sedimentary accretion and formed a certain cultural context in terms of function positioning, exhibition mode, evaluation criteria, theme selection and artistic form.

*This paper is one of the staged achievements of National Social Science Fund Art Project "Research on Chinese Contemporary Art System (19491989)" (Project No.: 16BF087)

\section{HIST ORICAL CONTEXT OF THE NATIONAL ART EXHIBITION}

From the inherent regularity, the National Art Exhibition mainly comprises a series of exhibition mechanism, which is the systematic guarantee for the continuation of the art exhibition; from the perspective of external orientation, it is made up of the value orientation and spirit of times of the exhibition, which are the external driving force of the exhibition. The inherent regularity and external directivity of the National Art Exhibition has constituted the life of the context of the art exhibition.

\section{A. Mainstream Value Orientation of the Country-External Orientation of the Exhibition}

The exhibition will inevitably reflect the country's cultural propositions and the country's cultural policy to a certain extent and it will follow the country's mainstream values as it is held in the name of the country. Xu Li, secretary general of China Artists Association, pointed out: "From the present perspective, all the fine art works that reflect truth, kindness, beauty and the current social life with practical significance and positive energy are the art creation with mainstream value of the socialism. The art creation with mainstream value of socialism also includes the artistic creation of historical theme, reflecting the profound Chinese culture and art works in Chinese history. It can be said that the art creation of socialist mainstream value is very macro, which not only refers to the present, but also links to history, covering the connotation of China's entire culture." [2] Reviewing the history of the development of National Art Exhibition, although its mainstream values have laid particular emphasis on certain aspect along with the changes of the times, the above statements have undoubtedly been covered in the basic demands of the National Art Exhibition, and gradually formed the guiding thinking principle in most people's minds.

This is to say the value orientation promoted by the National art Exhibition has always been the guideline for the judges and painters, and has been widely recognized by various people in the artistic circles. And it does not affect the painter to express various themes in a macro direction, which can be confirmed through the excellent works of each exhibition. The works of historical themes, such as Taihang Iron Wall by Wang Yingchun and Yang Lizhou, Silk and Music of Tang Dynasty by Xie Zhen'ou, 9 O'clock, September 9th, 1945. Nanjing by Chen Jian, Rosy Memories by Xing Qingren, Western Era by Luo Gen xing, Blood by Han Shuo, 1949 by 
Bai Zhanwang, show the righteousness and Chinese spirit. Some works truly reproduces history, and some others express history from a new perspective. The Taihang Iron Wall, which won the gold medal in Chinese painting, has been very successful and effective in inserting main theme of the times through refining, summarizing and processing of artistic form language in addition to expressing the historical theme in a creative way, which has effectively solved the topic of the times of respecting time changes and grasping healthy cultural spirit.

"A key point emphasized by the artistic creation with mainstream value of socialis $m$ is that our artis ts shall find and express beauty among people and in the real life, so as to express and carry forward the spirit of the times and reflect positive energy." [3] Art reflects the healthy, positive real life, which has always been the theme advocated by the state. Many works that pay close attention to people's livelihood and show sympathy for the hardships of people appear in each art exhibition since the new era. Such as the People and Prime Minister by Zhou Sicong, the most touching aspect is the feeling reflected in the painting, which connects the suffering of the affected people and the care from Prime Minister closely; Brackfast by Xin Dongwang shows that he is affected by migrant workers, conveying the workers' real life with passion, so as to express the concern about workers' inner spirit. In addition, People Mining Light by Li Shinan, Work Shed by Xu Weixin, and The Pillar by Cai Chao and Cai Qun express their compassionate feelings toward people, especially people at the bottom of society, as well as the excavation of their inner spirit.

To express the harmony and unity of truth, goodness and beauty is the eternal pursuit of art and the requirement of fine arts with mainstream value of socialism. Such works can be found in each of the previous exhibitions. For example, Green and Red by He Xiaoyun, one of the works winning gold medal of Chinese painting at the tenth Art Exhibition, expresses two female soldiers' firm, calm and confident expression facing the fashionable wo men on the street; Snow Wolf Commandos by Miao Zaixin reveals the standby state of a special-terrorist fighting unit of the Armed Police Force, with the faith of maintaining peach and the principle of serving the society. There are works describing natural beauty, such as Taihang Monument by Jia Youfu, Snow in Spring by Wu Guanzhong, Jiangnan Ancient Town by Yang Keyang and so on, and it can be said that these paintings express various aspects of the life in a multiple manner in terms of content and theme.

"Carry forward the main theme, and promote diversification". The pursuit of diversity under the socialist mainstream value orientation has always been our policy. In terms of creation techniques, in addition to realism, the abstractism, symbolism and other modernist practices learn from and integrate with each other, which enriched the artistic expression with Chinese cultural spirit. For example, the abstract works of Complementary Series N0.120 by Zhou Changjiang at the seventh Art Exhibition won silver award of oil painting, which is the first non-figurative painting that obtains such a high honor since our founding.

National Art Exhibition should pay equal attention to and unify the national will and academic principles. Since the new period, the complex multi-cultural exchange, mutual collision, and even mutual penetration in the national reform and opening up make the artistic creation in new era face enormous challenges. With the development of the times, the artist's aesthetic thought, artistic concept and his creative techniques also need to keep pace with the times. It is not difficult to imagine that in this case, a number of problems of National Art Exhibition may need to be resolved, but the contemporary artistic creation will not have a harmonious, healthy and sustainable development of a good cultural ecology without a pervading national mainstream values orientation that keeps pace with the times.

\section{B. Mechanism of National Art Exhibition-Inherent Regularity of Art Exhibition}

As a form of promoting the development of art, National Exhibition's mechanism and a series of its principles and measures are the system guarantee to inspect artistic creation, find and cultivate art talent as well as select the excellent works of art. In the various National Art Exhibitions over the years, it has formed a relatively stable basic process from soliciting contributions to direction selection and evaluation principle, and to how to set the gold, silver, bronze medals and how to hold the exhibitions:

A more complete system is formed in terms of organizational structure. The sponsors of the exhibition are the Ministry of Culture and China Artists Association, which were adjusted to Ministry of Culture, China Federation of Literary and Art and China Artists Association at the eleventh exhibition. [4] In terms of procedure, first of all, set up the organization committee, which comprises the honorary director, director and deputy director and a number of members, to take charge of the preparation and all kinds of works of the exhibition. The National Art Exhibition Office under Organization Committee shall be set up to perform specific implementation of various works of National Art Exhibition under the leadership of secretary-general. Various provinces, autonomous regions, municipalities directly under the Central Government and the Chinese People's Liberation Army shall set up the Organization Committee and Exhibition Office of the National Art Exhibition of its own region and system, to take charge of the creation, collection, evaluation and delivery of items on display of this region and system, and contact the National Art Exhibition organization committee and the National Art Exhibition Office at any time, to coordinate with each other for completion of various works of National Art Exh ibition jointly. [5]

The delivery of works and exhibition also change a lot. As for the delivery process, generally various regions send the works for exhibition, and then select the excellent ones from those works for display in each exhibition zone, and then decide on the awards in Beijing. Great reform has been made for the delivery of works for the eleventh art exhibition. The authors of all the paintings can submit their works to the exhibition zone directly except Chinese painting, oil painting, printmaking, watercolor and gouache. [6] The exhibition by exhibition area started from the Forth National Art Exhibition, which were displayed in six exhibition areas simultaneously in 1964 during the period of National Day, and then exhibit in 
China Art Museum in Beijing respectively. [7] With the development of the times, the exhibition areas have been added: Watercolor and powder exhibition areas were set separately at the sixth exhibition; at the ninth exhibition, while displaying at various exhibition areas, the art design exhibition was added; the lacquer painting, pottery exhibition area and animation exhibition area were added at the eleventh exhibition; at the twelfth exhibition, experimental art exhibition was added. As for the exhibition procedures, great change occurred in the eighth exhibition, which was divided into two stages, namely first of all, various provinces and cities hold exhibitions respectively, and then hold exhibition of excellent works in Beijing. Wang Qi said that: "We believe in the art as sociations of various regions fully, allowing them to organize the organization committee and judging panel without our interference. They shall be responsible for all the manpower and fund, and we concentrate on the excellent works exhibition. [8]

Since the ninth exhibition, the exhibition mode and schedule also formed a relatively fixed model. Generally, conduct the investigation of work at various exhibition areas as well as coordination and deployment meetings from December of the previous year of each exhibition to January of the current year. At the end of February, convene the working meeting of exhibition areas of National Art Exhibition. In the mid-to-late March, convene the working meeting of organization meeting. Start the evaluation from the end of May to early June. Complete the initial evaluation within June to August. Open the exhibition in various exhibition areas from August to October. In early November, decide on awards in Beijing. In early Dece mber to mid January 2015, hold the award-winning and award-winning nomination exhibition in China Art Museum within 40 days of exhibition. [9] The time changes a little for each exhibition, yet the workflow is relatively fixed.

The organization mode, evaluation mechanism and other procedures and standards of National Art Exhibition are established in the process of exhibition. From the perspective of historical development, the first five exhibitions were not explicitly institutionalized, namely there was no clear definition of holding the exhibition every five years. The institutionalization of National Art Exhibition started in the sixth National Art Exhibition in 1984. At the exhibition, the Ministry of Culture and the China Artists Association reformed the National Art Exhibition and evaluation methods, stipulating that the National Art Exhibition shall be sponsored by the Ministry of Culture and the Chinese Artists Association and held every five years in the future. In particular, the implementation of awarding system prior to the exhibition is the important reform of the sixth National Art Exhibition whole influence still plays a role at present, indicating the state pays highly attention to the cultural environment that keeps pace with the times. Starting from this exhibition, in addition to the issuance of certificate and bonuses, the National Art Exhibition also grants the gold, silver and copper medals. And the honor award was added, to issue to the older painters who bring their excellent works to the National Art Exhibition, aiming to encourage the artists "to create new art of socialism" under the premise of adhering to take economic construction as the center. [10]
As for the award criteria, there exist slight differences due to different times. The first several exhibitions after the founding of new China basically took the combination of policy and art as the selection criteria (mainly expressed the workers, peasants and soldiers in terms of the theme). Since the sixth exhibition, there had been a great change, highlighting "adhering to the policy of flourishing, requiring the diversity of theme, genre, style, and form"; at the ninth exhibition, "promoting the main theme and advocating diversification" was clearly put forward; The new standard of "excellent in thought, art and appreciation" was used in the evaluation of works at the tenth art exhibition. It can be seen that the latter is more inclusive from the changes in policies.

The development of evaluation methods and evaluation criteria will finally fall on the operation of judges. The judging panel is usually composed of highly respected artists and art theorists. The judging panel of the eleventh National Art Exhibition was reformed, which was divided into three parts: the provincial (autonomous regions and municipalities) judging panel, the judging panel at exhibition area and the general judging panel. Among them, a considerable proportion of judges of provincial (autonomous regions and municipalities) judging panel will be invoked by the National Art Exhibition organization committee in a nationwide scale. The judges of judging panel at the exhibition area comprises part of the experts from the "expert library" of various exhibition areas. And the proportion of young members in the judging panel is much higher than before. [11] In order to be fair, the China Artists Association also designed a set of scoring software, and announced the results immediately under the one-site supervision of national notaries, which are to ensure the objectivity of the evaluation results.

In order to encourage more artists to participate in the exhibition, and to supervise and boom the artistic creation, the National Art Exhibition organizations shall carry out mobilization of the exhibition. For instance, issue the art exhibition documents, the experts of art exhibition visit various regions and provide guidance, solicit opinions about the exhibition; organize the art theorists and painters to convene workshop in the exhibition, and organize the winner to discuss creation experience and organize the judges to talk about their ideas about the exhibition after exhibition, and so on. Find the positive factors and various problems in artistic creation through interaction of all aspects, aiming to improving the creation level and adhere to the correct orientation.

\section{JOYS AND SORROWS: REFLECTIONS ON THE DILEMMA OF NATIONAL ART EXHIBITION}

Although the sponsor of exhibition makes efforts to carry out all aspects of the exhibition, there will be some inevitable loopholes or biases. It is because the problems of the exhibition itself on the one hand; on the other hand, it is difficult to cater for all tastes and it is impossible to meet the wishes of all art workers. For instance, as for the channel for delivery art works to the exhibition, relative loopholes or unfair phenomenon will generate in the screening at various levels. In the quota allocation of in various provinces, it is easy to generate limitations from interpersonal relationship and aesthetic vision of the judges, as well as the unreasonable allocation of quota in 
the provinces. In the final evaluation stage, the composition of the judges, the review process and the personal experience of judges, aesthetic character, etc. may affect judge on the works.

Some divergent views come out in terms of the selected proportion distribution of the exhibition painting, the proportion of region, the landscape, flowers and birds, figure painting selection or award-winning ratio: some people "redress grievances" for the small number of selected types of painting. For instance, Zhou Guangzhen had written that "compared to 300 pieces of lacquer paintings, there were only 120 pieces of pottery" [12], complaining for the ceramic art workers; some "feel wronged" for the allocated quota, Tuo Musi, one of the judges of the ninth art exhibition, complained that Tibet was not included; some object the non-inclusion. Another example, the gold medal of landscape painting of previous National Art Exhibitions were absent and so on, indicating that all sectors attach importance to and take care of the National Art Exhibition while expressing dissatisfaction.

Reviewing the history, inevitable loopholes and biases may exist in the award evaluation due to the normalization set by the standards, yet the art is featured by openness and exploration. Ye Qianyu, one of the judges of the sixth exhibition, said that: "In the evaluation, we shall aware that, as a judge, we cannot look at the works with the view of ordinary viewers, and cannot view other works rely on one professional standard; we must proceed from the overall situation, to view both the current situation and history, the individual and the entirety, so as to evaluate in an objective and fair manner as far as possible. But in fact, it is impossible to completely exclude the subjective preference, so we have to admit that the evaluation of art can only be close to fair, because the standards of art are quite complex." [13] This has not only revealed the inevitable biases of the judges at the time of judging and the embarrassment difficult to be measured by the standards of art; in addition, it indicates that the research of evaluation methods and evaluation criteria is a problem need to be solved urgently. Furthermore, after the theme and artistic requirements is put forward for an exhibition at national level, "some artists misinterpret such theme with some kind of mentality, and such works have been confirmed by the sponsors, which has become a classic routine, used by generations of artists, and finally form the dilemma of having "theme" yet without real thoughts and spirit. [14]

\section{CONCLUSION}

The overall image of National Art Exhibition has a logical continuity with the hundred years of art development in terms of context, and can be integrated with the future development of Chinese culture. Its different voices show the high attention of times, which is the reflection that the government, painters and audiences have great expectations on it. Through sorting the historical development context of the National Art Exhibition, it can be found that it has precipitated a set of exhibition system. This system updates its internal mechanism and external orientation in accordance with the Party's literary policy constantly along with the times and changes in the problems faced by it and are full of new vitality. National Art Exhibition leads Chinese art culture to be positive and progressive in terms ideology through the combination of national will and folk thought, leading the "style of the times", "the tendency of the times", and establish a good platform for the excellent works organically unifying "thought, art and appreciation". As a guidance, awarding system makes the painter clearly know "what should be affirmed and praised, what should be objected and denied", to create an excellent work with "concurrent beauty of form and content", so as to lead the mass of the people to "establish and adhere to the correct view of history, national viewpoint, nation concept and cultural concept "[15], to boom the artistic creation and create a good art atmosphere, which is the significance of endless his torical and cultural context of the National Art Exhibition.

\section{REFERENCES}

[1] http://baike.so.com/doc/5285661 html.

[2] Hao Bin. The Twelfth National Art Exhibition Highlights the Spirit of Chinese Culture and the Spirit of the Times — - an Interview with China Artists Association Secretary - General Xu Li Regarding Relevant Problems of the T welfth National Art Exhibition, ART, 2014, No.4

[3] Hao Bin. The Twelfth National Art Exhibition Highlights the Spirit of Chinese Culture and the Spirit of the Times - - an Interview with China Artists Association Secretary - General Xu Li Regarding Relevant Problems of the T welfth National Art Exhibition, ART, 2014, No.4

[4] Yang Ping. New Measures of the Eleventh National Art Exhibition Demonstrate a Self-reinforcing Cult ure, China Art, June 12, 2009.

[5] Referring to the Implementation Details of the Exhibition of various National Art Exhibitions.

[6] Yang Ping. New Measures of the Eleventh National Art Exhibition Demonstrate a Self-reinforcing Culture, China Art, June 12, 2009.

[7] Editorial Department of this Publication: Review and Prospect of National Art Exhibition, ART, 1965, No. 6.

[8] Chen Qian. Interview with the Judges of the Eighth National Art Exhibition, ART, 1995, No.2.

[9] Referring to Yang Ping. Question \& Answer about Implementation Det ails of the Twelfth National Art Exhibition Area, ART, 2014, No.4.

[10] The Sixth National Art Exhibition Office Answers the Reporters' Request about Exhibition and Rewarding, ART, 1983, No.12

[11] There will be Four Major Changes in Eleventh National Art Exhibition, The Contemporaries, 2009, No.4

[12] Zhou Guangzhen. Comment on the Lack of Planning for National Art Exhibition and Redress an Injustice for 100,000 Ceramist, Ceramic Science and Art, 2009, No.9

[13] Ye Qianyu. Enlightenment of the Sixth National Art Exhibition, ART, 1985, No.2

[14] Zhang Xiaoling. My Views on the Works of Nine Art Exhibitions, Art Observation, 2000, No.2

[15] Xi Jinping. Art shall not be covered with Odor of Money. http://news.sina.com.cn/c/2014-10-15/212230994688.shtml. 